\title{
PLANNING AND IMPLEMENTATION OF THE "LIBRARY OF DIPANEGARA" AT STMIK LIBRARY"
}

\author{
Muhammad Syaiful S1 dan Irvan Muliyadi ${ }^{2}$ \\ 1\&2Universitas Islam Negeri Alauddin Makassar \\ Correspondence email: irvanmuliyadi71@gmail.com
}

\begin{abstract}
Activities carried out in the library, starting from inputting, collecting data, to services when it is done manually, will certainly cause several obstacles and require a lot of time. Libraries as a media that in their activities to collect, to organize, or to maintain library materials, must be supported by the present of fast and accurate information. Therefore, it is necessary to have an information system in the library. This study will describe "Library Dipanegera" as a new service. This information system is aims to facilitate librarians in the circulation area. This system has several features such as book entry, book data, member data, book borrowing and return. This information system is created using the PHP programming language and MySQL for its database. This system uses the Blackbox testing method. The results of this study showed that an information system is needed so that can facilitate librarian in circulation services in the library.
\end{abstract}

Keywords : Library information system,

\begin{abstract}
Abstrak
Kegiatan yang dilakukan di perpustakaan mulai dari penginputan, pendataan, hingga pelayanan ketika itu dilakukan secara manual tentu akan menimbulkan beberapa hambatan serta membutuhkan banyak waktu. Perpustakaan sebagai wadah yang dalam aktivitasnya menghimpun, mengatur, ataupun merawat bahan pustaka, harus didukung dengan penyajian informasi yang cepat dan akurat. Oleh karena itu perlu adanya sistem informasi di perpustakaan.Rancangan sistem informasi ini bertujuan untuk memudahkan pustakawan dan pemustaka dalam proses sirkulasi di perpustakaan. Dalam penelitian ini penulis menggunakan metode pengambilan data secara kualitatif. Sedangkan instrumen untuk pengumpulan data yang digunakan yaitu observasi, wawancara, dan studi literatur. Sistem ini memiliki beberapa fitur seperti penginputan buku, data buku, data anggota, peminjaman dan pengembalian buku. Sistem informasi ini dibuat menggunakan bahasa pemrograman PHP dan MySQL untuk basis datanya. Sistem ini mengggunakan metode pengujian Blackbox. Dari hasil penelitian ini menghasilkan sebuah sistem informasi yang dapat memudahkan pustakawan dalam pelayanan sirkulasi di perpustakaan.
\end{abstract}

Kata kunci: Sistem informasi perpustakaan 


\section{Pendahuluan}

Teknologi informasi berkembang sangat pesat sehingga mempuyai dampak dalam peningkatan efektifitas dan keefisienan dalam melakukan setiap pekerjaan.Informasi dapat diperoleh dengan cepat, akurat dan mudah diketahui oleh pengguna dengan adanya sistem informasi.

Dengan sistem informasi, pengguna diberikan kemudahan dalam mengerjakan sesuatu pekerjaan atau mengakses sebuah sistem informasi yang akhirnya memberikan dampak pekerjaan menjadi mudah. Misalnya Pekerjaan yang tadinya harus dikerjakan secara manual kini tergantikan dengan penggunaan sistem informasi. Perkembangan teknologi informasi juga berpengaruh pada perpustakaan.

Dalam perpustakaan Stmik Dipanegara Makassar saat ini masih berbasis konvensional. Dalam proses peminjaman, pengembalian dan pendataan buku biasanya dicatat di sebuah buku dengan menulisnya secara manual.Dalam meningkatkan mutu perpustakaan STMIK Dipanegara Makassar, maka perlu adanya sistem informasi diterapkan di perpustakaan. Dengan demikian penulis meneliti tentang bagaimana perancangan sistem informasi "Library Of Dipanegara" dan bagaimana penerapan sistem informasi "Library Of Dipanegara" di perpustakaan STMIK Dipanegara Makassar.

\section{Metodologi}

Penelitian ini menggunakan metode applied research. Untuk menyelesaikan rancangan sistem informasi "Library Of Dipanegara", maka penulis melakukan penelitian berdasarkan metode yang dijalankan secara bertahap dengan menggunakan pendekatan kualitatif untuk memperoleh gambaran secara terperinci perihal analisis perancangan sistem informasi agar sistem informasi yang dihasilkan sesuai dengan yang diharapkan. Dalam upaya untuk memperoleh sebuah informasi sesuai dengan objek penelitian yang lengkap, akurat, objektif, dan dapat dipertanggungjawabkan terkait kebenaran yang ada di lapangan.Berkaitan dengan teknik ataupun upaya pengumpulan data yang digunakan dalam penelitian ini, maka peneliti menggunakan field research, yaitu mengumpulkan data melalui penelitian lapangan, dengan menggunakan metode sebagai berikut :observasi, wawancara, dan dokumentasi.

Sistem dalam Kamus Besar Bahasa Indonesia (KBBI) merupakan perangkat unsur yang secara teratur saling berkaitan sehingga membentuk suatu totalitas. (Asmara, Sistem Informasi Pengolahan Data Penanggulangan Bencana Pada Kantor Badan Penanggulangan Bencana Daerah (BPBD) Kabupaten Padang Pariaman, 2016) sistem adalah sekelompok dua atau lebih komponen yang saling berkaitan (subsistem-subsistem yang bersatu untuk mencapai tujuan yang sama).

(Hutagalung, 2018)Sistem informasi perpustakaan adalah suatu sistem di dalam organisasi pelayanan publik yang mempertemukan kebutuhan pengelolaan transaksi peminjaman, pengembalian, perpanjangan buku, dan pembuatan laporan 
harian, bulanan ataupun tahunan guna mendukung operasi bersifat manajerial dan kegiatan dari suatu organisasi.

Perancangan Sistem Informasi Perpustakaan dengan menggunakan metodologi waterfall. Model pengembangan sistem waterfall ini mengambil kegiatan proses dasar seperti spesifikasi, pengembangan, validasi, dan evolusi serta mempresentasikannya sebagai fase-fase proses yang berbeda seperti spesifikasi persyaratan, perancangan, perangkat lunak, implementasi, dan pengujian. (Kusnandar).

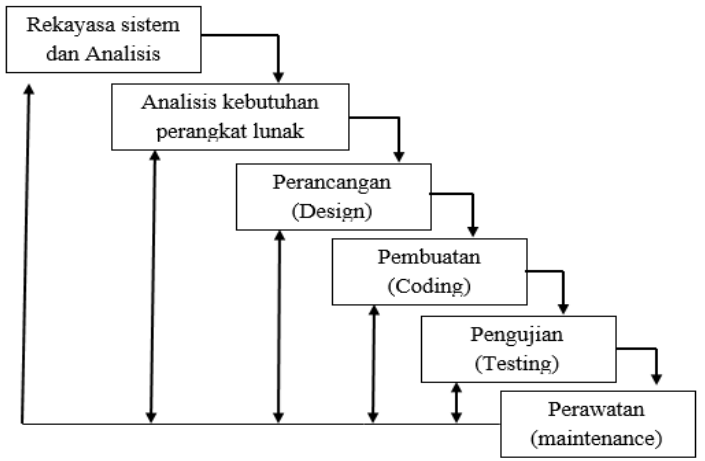

Gambar 1.Gambar Model Waterfall (Jogiyanto,2010)

Tahapan-tahapan dari metode waterfall adalah sebagai berikut.

a. Observasi

Kegiatan observasi dilakukan di perpustakaan Stmik Dipanegara Makassar dimaksudkan untuk menganalisis permasalahan yang terjadi di lokasi.

b. Analisa Kebutuhan Sistem

Berdasarkan hasil observasi yang telah dilakukan, maka penulis akan merancang sebuah sistem informasi perpustakaan berbasis website untuk memudahkan pustakawan maupun pemustaka dalam proses sirkulasi di perpustakaan.

c. Perancangan Sistem

Perancangan sistem dalam penelitian ini terlebih dahulu akan dibuatkan UML (Unifed Modeling Language) dan ERD (Entity Relationship Diagram).

d. Pembuatan Sistem

Pembuatan sistem pada penelitian ini menggunakan bahasa pemrograman PHP dan database yang digunakan adalah MySQL.

e. Pengujian Sistem

Sebelum diterapkan atau di implementasikan sistem yang telah dirancang terlebih dahulu akan dilakukan pengujian yang bertujuan untuk mengetahui terjadinya error pada sistem. Pengujian sistem dilakukan menggunakan metode pengujian blackbox. 


\section{f. Perawatan (Maintenance)}

Perawatan sistem dilakukan dengan mengadakan perubahan, penambahan, koreksi bila diperlukan, dan backup database secara berkala selama operasional sistem yang dirancang.

Dalam perancangan sistem informasi perpustakaan ini, penulis menggunakan metode System Development Life Cycle (SDLC). SDLC merupakan pola yang diambil untuk membangun sistem informasi melalui beberapa tahap. Secara keseluruhan ada beberapa model SDLC, namun penulis memakai model SDLC waterfall yang cukup marak digunakan.

(Dari, 2015) Dalam sebuah siklus SDLC terdapat 7 langkah. Siklus perancangan sistem ini dapat diuraikan dalam tahapan sebagai berikut:

1. Perencanaan (Planning)

Pada tahap ini merupakan langkah awal dalam pembuatan sistem. Merencanakansebuah konsep sistem apa yang diinginkan dan tentunya berkaitan dengan proyek sistem informasi yang akan dibuat.

2. Analisa (Analysis)

Pada tahap ini dilakukan analisis terhadap alur kerja manajemen sistem.

3. Desain (Design)

Pada tahap ini dilakukan perancangan alur manajemen dan penggambaran perancangan yang akan dibuat. Ada dua jenis desain yang akan dibuat dalam sistem informasi ini, yaitu desain proses bisnis dan desain pemrograman.

4. Pengembangan (Development)

Tahap ini yaitu melakukan proses transfer dari hasil rancangan ke dalam coding bahasa pemrograman.

\section{Testing}

Pada tahap ini yaitu melakukan pengujian sistem yang telah dibuat.

\section{Implementasi}

Pada tahap ini yaitu proses menerapkan sistem informasi yang telah dibuat sebelumnya dan akan digunakan oleh user.

7. Pengoperasian \& Pemeliharaan (Operations \& Maintenance)

Pada tahap ini yaitu kegiatan dalam mengoperasikan sistem oleh user dan kegiatan pemeliharaan yang dilakukan oleh administrator agar sistem tetap up to date.

\section{Hasil Penelitian}

Analisis Sistem merupakan proses penguraian sistem ke berbagai komponennya dengan cara mengidentifikasi masalah yang muncul pada sistem sehingga nantinya dapat ditemukan solusi dan permasalahan tersebut. 
Berdasarkan hasil observasi tanggal 14-18 Januari 2020, menunjukkan bahwa pelayanan di perpustakaan stmik dipanegara makassar masih lambat karena ratarata pustakawan menghabiskan banyak waktu untuk melayani satu pemustaka. Dengan demikian maka diperlukan adanya sistem informasi di perpustakaan stmik dipanegara agar pelayanannya menjadi efektif dan efisien.

Berdasarkan hasil wawancara yang dilakukan peneliti perihal kebutuhan sistem informasi yang diinginkan oleh pihak pustakawan stmik dipanegara makassar, maka peneliti menyimpulkan kebutuhan sistem nya sebagai berikut.

1) Sistem ini menampilkan halaman search box, sebagai proses antar user dengan sistem.

2) Sistem ini akan menampilkan berbagai macam data seperti data anggota, data buku, serta data peminjaman bahan pustaka.

3) Sistem yang dirancang akan memiliki antarmuka yang mudah digunakan bagi pemustaka.

a. Implementasi Sistem

1. Halaman Login Admin

a). Antarmuka Tampilan Awal Sistem

Antarmuka tampilan awal tampil pada saat user mengakses sistem. Jadi sebelum masuk ke menu login, tampilan home sebuah sistem informasi akan menampilkan sebuah layar utama.

\section{Library Of Dipanegara}

SELAMAT DATANG DI SISTEM INFORMASI PERPUSTAKAAN

Gambar 2. Antarmuka Tampilan Awal Sistem

b). Antarmuka Login Admin

Antarmuka login tampil pada saat pustakawan akan mengakses sistem. Jadi sebelum mengakses sistem, pustakawan harus login terlebih dahulu. Antar muka login menampilkan kolom untuk login user. 


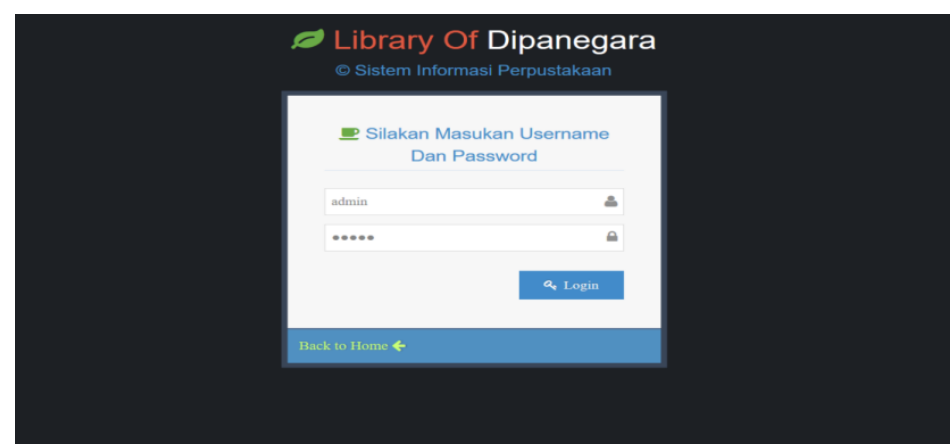

Gambar 3.Antarmuka Login Admin

c). Antarmuka Halaman Dashboard

Antarmuka dashboard akan tampil saat sistem pertama kali diakses setelah user login. Pada antarmuka ini user akan melihat grafik peminjaman perbulan, grafik peminjaman terbanyak berdasarkan judul buku, grafik peminjaman buku berdasarkan jenis kategori/ disiplin ilmu, dan grafik peminjaman buku terbanyak berdasarkan kelas/jurusan

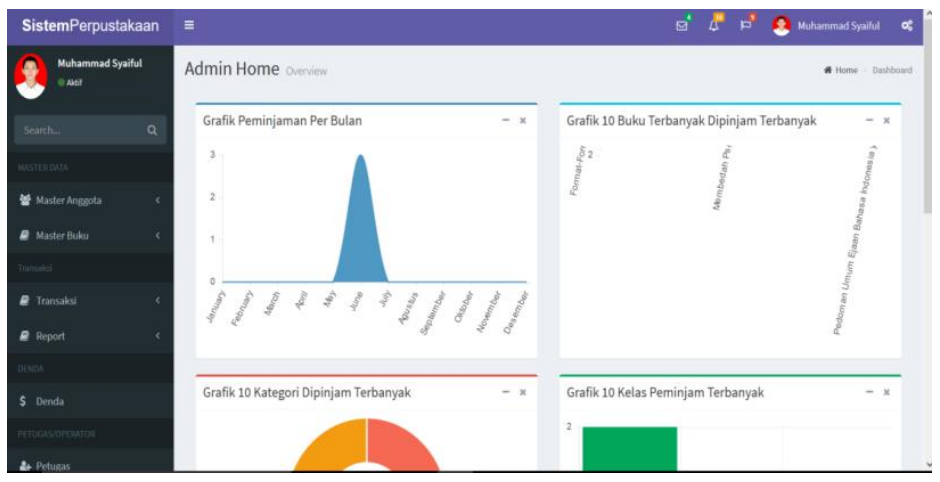

Gambar 4. Antarmuka Halaman Dashboard

d). Form Input Data Peminjaman Dan Pengembalian

Penginputan data user peminjaman dan pengembalian akan tampil pada saat user telah login ke sistem. Dan ketika user menginginkan menginput data peminjaman atau pengembalian buku oleh pemustaka maka selanjutnya akan menampilkan form penginputan data user peminjaman dan pengembalian. 


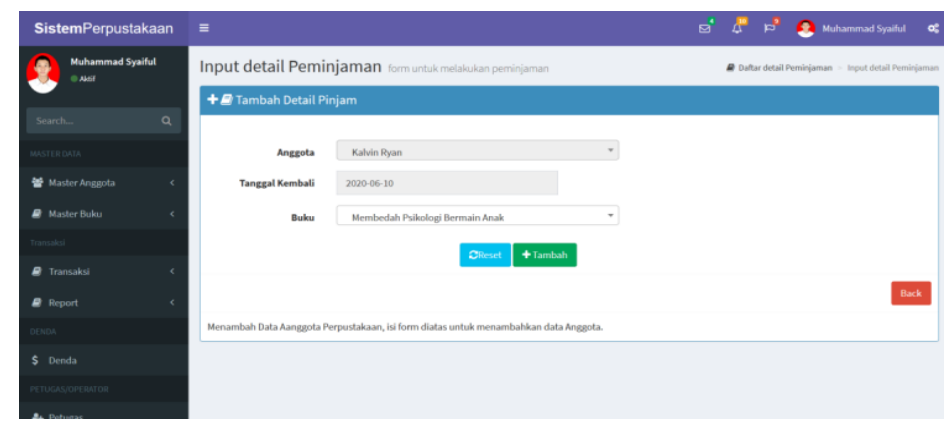

Gambar 5.Form Input Data Peminjaman Dan Pengembalian

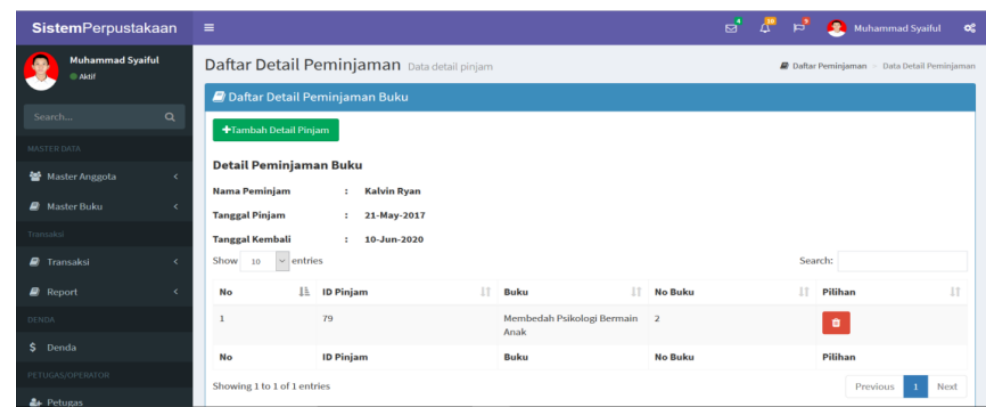

Gambar 6. Form Input Data Peminjaman Dan Pengembalian e). Form Antarmuka Daftar User Peminjaman Dan Pengembalian

Antar muka daftar user akan tampil setelah pustakawan melakukan penginputan data user peminjaman dan pengembalian buku.

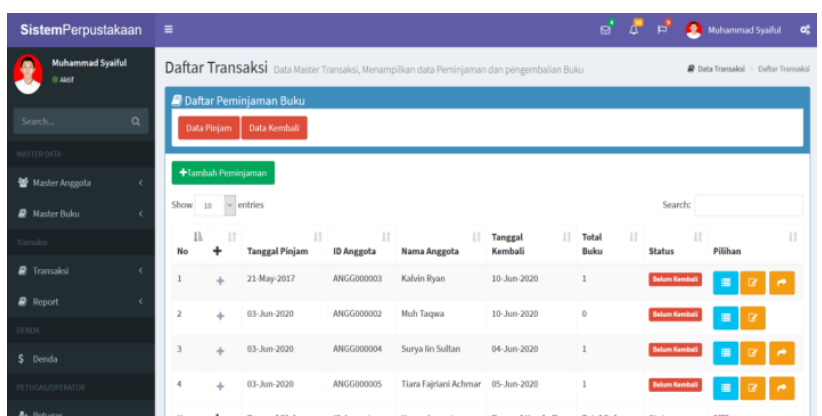

Gambar 7. Gambar Form Daftar User Peminjaman Dan Pengembalian

f). Form Input Kartu Anggota

Penginputan data user kartu anggota akan tampil saat user telah login ke sistem. Dan akan menampilkan penginputan data user kartu anggota. 


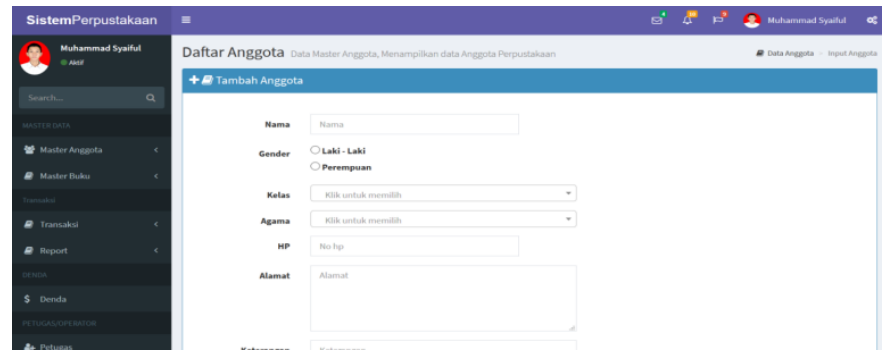

Gambar 8 Form Input Kartu Anggota

g). Form Daftar Kartu Anggota

Form daftar data anggota akan tampil saat user telah melakukan penginputan data anggota. Dan akan menampilkan form penginputan data user kartu anggota.

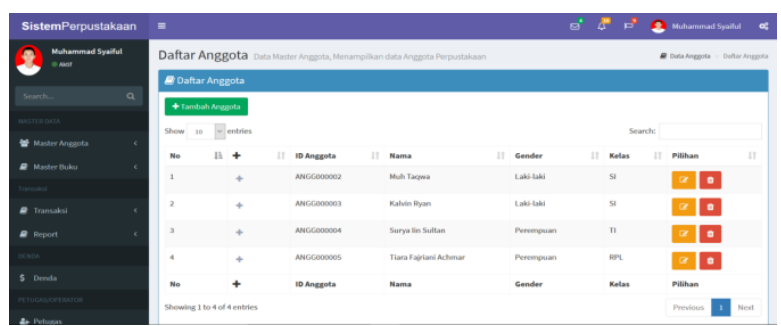

Gambar 9. Form Daftar Kartu Anggota

h). Form Input Buku

Antar muka input data buku akan tampil pada saat ingin melakukan penginputan data buku.

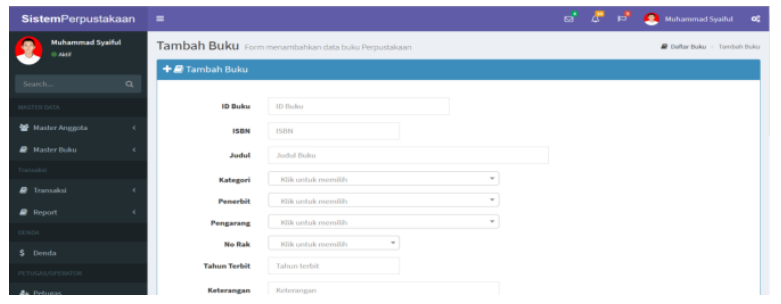

Gambar 10. Form Input Buku

i). Form Daftar Buku

Form daftar data buku akan tampil saat user telah melakukan penginputan data buku. Dan akan menampilkan form penginputan data buku. 


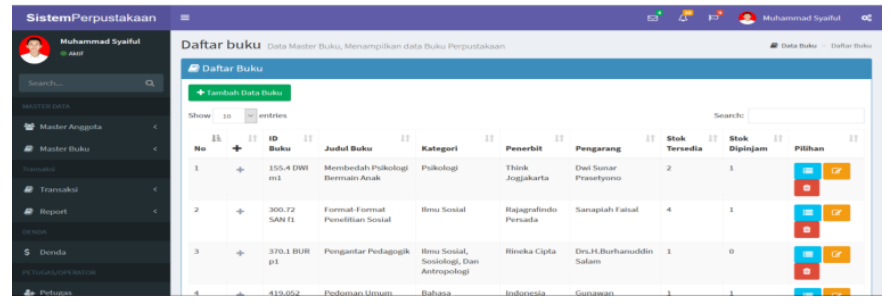

Gambar 11. Form Daftar Buku

\section{j). Form Daftar Denda}

tampilan menu ini saat pemustaka telat mengembalikan buku, dan form daftar denda akan tampil sesuai dengan jumlah yang telah diatur oleh pustakawan.

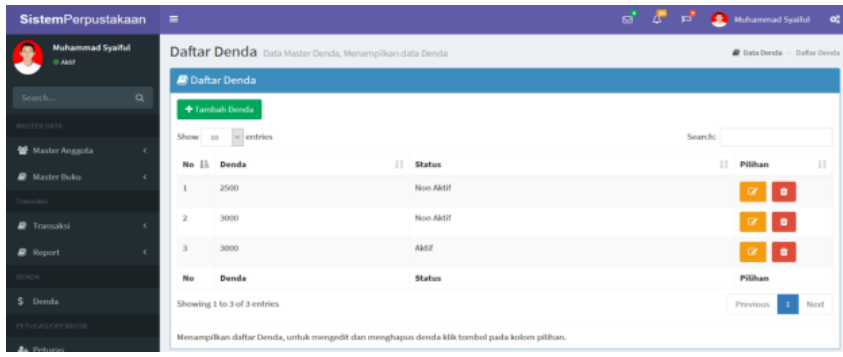

Gambar 12. Gambar Form Daftar Denda

\section{Halaman Search Box User}

Halaman search box khusus tampilan antarmuka yang disediakan untuk pemustaka. Jadi menu ini dikhususkan untuk pemustaka untuk mencari sebuah buku dan keterangan per buku akan menampilkan apakah buku yang dicari tersedia atau dipinjam.

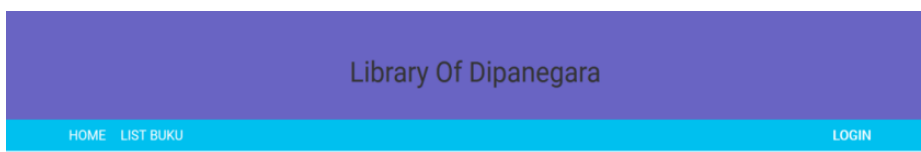

DATA BUKU PERPUSTAKAAN

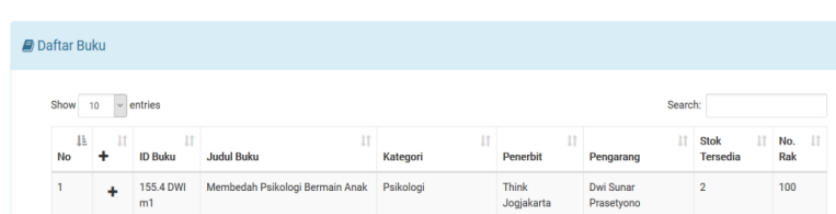

Gambar 13. Antarmuka Searchbox User 


\section{b. Penguïan Sistem}

(Dhega Febiharsa, 2018) Black-Box Testing merupakan pengujian perangkat lunak yang merupakan tes fungsionalitas dari aplikasi yang tidak mengacu pada struktur internal atau tidak membutuhkan pengetahuan khusus pada kode program aplikasi dan pengetahuan. Ujicoba Black-Box dilakukan untuk menemukan kesalahan dalam beberapa kategori yaitu: (1) Fungsi-fungsi yang hilang atau salah; (2) Kesalahan desain antarmuka (interface) atau tampilan; (3) Kesalahan dalam struktur data atau akses database ekternal; (4) Kesalahan performa; dan (5) Kesalahan inisialisasi dan terminasi.

1. Pengujian Sistem Antarmuka User

Tabel 1. Pengujian Sistem Antarmuka User

\begin{tabular}{|c|c|c|}
\hline Data yang Dimasukkan & Data yang diharapkan & Kesimp \\
\hline $\begin{array}{l}\text { Menu Login (Masukkan } \\
\text { Username \& Password, lalu } \\
\text { klik login }\end{array}$ & $\begin{array}{l}\text { Dapat masuk ke halaman } \\
\text { utama/ dashboard }\end{array}$ & $\begin{array}{l}{[\sqrt{ }] \text { Diterima }} \\
{[] \text { Ditolak }}\end{array}$ \\
\hline
\end{tabular}

2. Pengujian Peminjaman Buku

Tabel 2. Pengujian Peminjaman Buku

\begin{tabular}{llll}
\multicolumn{1}{c}{ Data yang Dimasukkan } & Data yang diharapkan & Kesimpu \\
Input Data Peminjaman & $\begin{array}{l}\text { Data dapat disimpan } \\
\text { sesuai penomoran } \\
\text { peminjaman yang } \\
\text { otomatis }\end{array}$ & {$[\sqrt{ }]$ Diterima } \\
Klik Menu Tambah Detail & $\begin{array}{l}\text { Data dapat ditambah } \\
\text { sesuai yang diharapkan }\end{array}$ & {$[\sqrt{ }]$ Diterima } \\
Peminjaman & {[] Ditolak }
\end{tabular}

3. Pengujian Pengembalian Buku

Tabel 3. Pengujian Data Buku

\begin{tabular}{cll} 
Data yang Dimasukkan & Data yang diharapkan & Kesimpulan \\
\hline Input Data Peminjaman & $\begin{array}{l}\text { Data dapat disimpan } \\
\text { sesuai penomoran } \\
\text { peminjaman yang }\end{array}$ & {$[\sqrt{ }]$ Diterima } \\
\hline
\end{tabular}


otomatis

Klik Menu Tambah Detail Peminjaman

Data dapat ditambah sesuai yang diharapkan $[\sqrt{ }]$ Diterima

[] Ditolak

Tabel 4. Pengujian Pengembalian Buku

$\begin{array}{cll}\text { Data yang Dimasukkan } & \text { Data yang diharapkan } & \text { Kesimpulan } \\ \text { Input Data Pengembalian } & \begin{array}{l}\text { Dapat disimpan sesuai } \\ \text { dengan yang diharapkan }\end{array} & {[\sqrt{ }] \text { Diterima }} \\ & {[] \text { Ditolak }}\end{array}$

4. Pengujian Data Buku

Tabel 5.Pengujian Pengimputan Buku

\begin{tabular}{lll} 
Data yang Dimasukkan & Data yang diharapkan & \multicolumn{1}{c}{ Kesimpulan } \\
\hline Input Data Buku & $\begin{array}{l}\text { Data dapat disimpan } \\
\text { sesuai dengan yang } \\
\text { diharapkan }\end{array}$ & {$[\sqrt{ }]$ Diterima } \\
Klik Tombol Tambah & Data dapat disimpan & {$[\sqrt{ }]$ Diterima } \\
& & {[] Ditolak }
\end{tabular}

\section{Diskusi dan Kesimpulan}

Adapun kesimpulan yang dapat diambil dari penelitian ini yaitu rancangan halaman login admin dan halaman search box user, dimana pada halaman login admin terdapat antarmuka Tampilan awal sistem, antarmuka login admin, antarmuka halaman dashboard, form input data peminjaman dan pengembalian, form antarmuka daftar user peminjaman dan pengembalian, form input kartu anggota, form daftar kartu anggota, form input buku, form daftar buku, dan form daftar denda.Sistem ini juga dapat menampilkan informasi tentang data buku perpustakaan baik yang tersedia maupun yang masih dalam peminjaman serta sistem ini dirancang untuk memudahkan pustakawan maupun pemustaka dalam pencarian dan peminjaman buku.

Sistem informasi perpustakaan ini dapat digunakan sebagai media informasi dan dapat memudahkan dalam pengelolaan perpustakaan karena sistem telah berjalan sesuai dengan fungsinya. Hal ini dibuktikan berdasarkan pengujian blackbox yang 
telah dilakukan. Semua sistem informasi mempunyai tiga kegiatan utama, yaitumenerima data sebagai masukan (input), kemudian memprosesnya denganmelakukan penghitungan, penggabungan unsur data, pemutakhiran dan lain-lain, akhirnya memperoleh informasi sebagai keluarannya (output).

\section{Daftar Pustaka}

Asmara, R. (2016). Sistem Informasi Pengolahan Data Penanggulangan Bencana Pada Kantor Badan Penanggulangan Bencana Daerah (BPAD) Kabupaten Padang Pariaman). Padang: Jurnal J-Click Vol 3 No 2 .

Asmara, R. (2016). Sistem Informasi Pengolahan Data Penanggulangan Bencana Pada Kantor Badan Penanggulangan Bencana Daerah (BPBD) Kabupaten Padang Pariaman. Jurnal J-Click Vol 3 No 2 , 80-91.

Dari, W. (2015). Penerapan Metode System Development Life Cycle Pada Pembuatan Sistem Informasi Penjualan Produk Batik Kurowo Jakarta. Jurnal Khatulistiwa Informatika, Vol.3, No.2 , 222-228.

Dhega Febiharsa, I. M. (2018). Uji fungsionalitas (blackbox testing) sistem informasi lembaga sertifikasi profesi (Silsp) batik dengan apperfect web test dan uji pengguna. Semarang: Joined Journal.

Hutagalung, D. D. (2018). Rancang Bangun Sistem Informasi Perpustakaan Berbasis Web Pada SMK Citra Negara Depok. Jurnal Rekayasa Informasi Vol 7 No 1, 13-22.

Kusnandar. (n.d.). Rancang Bangun \& Analisis Sistem Informasi Perpustakaan Menggunakan Metode Waterfall (Studi Kasus: Stmik Wicida Samarinda). Sebatik STMIK Wicida, 16-25. 